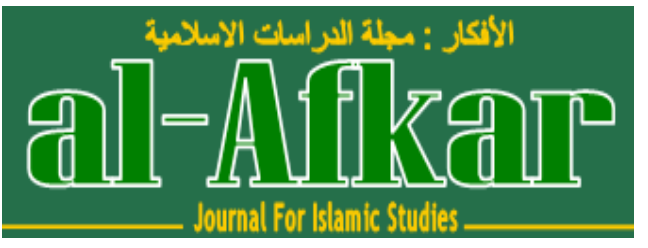

Vol. 2, No. 2, July 2019

P-ISSN : 2614-4883; E-ISSN : 2614-4905

https://al-afkar.com/index.php/Afkar_Journal/issue/view/4

DOI: https://doi.org/10.31943/afkar_journal.v4i1.70

\title{
PEMIKIRAN FIKIH KEMASLAHATAN DAN FIQIH AKHLAK (Membaca Kembali Kitab Bidâyatul Mujtahid wa Nihâyatul Muqtashid karya Ibn Rusyd)
}

\author{
Zaenudin Abu Bakar \\ Fakultas Agama Islam Universitas Wiralodra \\ E-Mail: zaenudino86@gmail.com

\section{Ibnu Rusydi} \\ Fakultas Agama Islam Universitas Wiralodra \\ E-Mail: ibnurs@gmail.com
}

\begin{tabular}{|c|c|c|}
\hline Received & Revised & Accepted \\
\hline 3 Juny 2019 & 20 Juny 2019 & 1 July 2019 \\
\hline
\end{tabular}

\section{THE THINKING OF PROSPERITY AND MORAL IN FIQH (Reread of the Book of Bidâyatul Mujtahid wa Nihâyatul Muqtashid by Ibnu Rusyd)}

\begin{abstract}
The Book of Bidāyatul mujtahid whose full title is Bidâyatul mujtahid wa nihâyatul muqtashid is the work of Ibn Rushd in the field of Jurisprudence which is the most famous and most qualified when compared to his other Jurisprudence books. Basically, the view of fiqh Ibn Rushd was no different from the previous fiqh scholars in terms of the relationship between Shari'a and benefit. What distinguishes between Ibn Rushd and the others is the emphasis. If the Jurists emphasized the benefit and interests, Ibn Rushd emphasized his views on the moral side. He believes that the Shari'a was born to improve human morals. In this case El Abidi stated that Ibn Rusyd was the only Jurist who built the objectives of the Shari'a on a moral foundation (morals).
\end{abstract}

Keywords: Fiqh, Benefit, Ibn Rushd, Bidayatul Mujtahid 


\begin{abstract}
Abstrak
Kitab Bidâyatul mujtahid yang judul lengkapnya adalah Bidâyatul mujtahid wa nihâyatul muqtashid adalah karya Ibn Rusyd dalam bidang Fikih yang paling terkenal sekaligus paling berkualitas jika dibandingkan dengan buku-buku Fikihnya yang lain. Pada dasarnya, pandangan fikih Ibn Rusyd tidak berbeda dengan para ulama fikih sebelumnya dalam hal hubungan antara syariat dengan kemaslahatan. Yang membedakan antara Ibn Rusyd dan yang lainnya adalah penekanannya saja. Jika para ahli fikih menekankan sisi kemaslahatan dan kepentingan, Ibn Rusyd menekankan pandangannya pada sisi moral. Ia berpendapat bahwa syariat itu lahir untuk memperbaiki akhlak manusia. Dalam hal ini El Abidi menyatakan bahwa Ibn Rusyd adalah satu-satunya ahli fikih yang membangun tujuan syariat di atas fondasi moral (akhlak).
\end{abstract}

\title{
Kata Kunci: Fiqih Kemaslahatan, Ibnu Rusyd, Bidayatul Mujtahid
}

\section{Pendahuluan}

Ibn Rusyd adalah salah seorang sosok ilmuwan muslim abad ke-12 M yang memiliki jasa yang besar bagi peradaban Islam dan juga bagi orang-orang Barat. Karena dari terjemahan karya-karyanyalah dinamika berpikir mereka terbuka sehingga menghasilkan apa yang disebut dengan era pencerahan (renasissance) sebagai manifestasi peradaban Barat yang hingga kini masih mendominasi dunia. Maka dari itu, tak heran jika tulisan-tulisan yang berkaitan dengan peradaban Islam, khususnya dalam bidang pemikiran Islam, terasa tidak lengkap tanpa kehadiran Ibn Rusyd.

Dari segi filsafat, Ibn Rusyd dapat dikatakan telah mendapatkan haknya untuk dikaji dan diteliti. Begitu banyak tulisan, baik berupa makalah, jurnal, maupun buku-buku ilmiah yang mengangkat masalah filsafat Ibn Rusyd baik secara historis, metodologis maupun ontologis.

Tapi, sebagai ilmuwan yang juga aktif dalam bidang Fikih, Ibn Rusyd tampaknya belum mendapatkan penghargaan yang selayaknya. Riwayat hidupnya yang penuh dengan warna-warni fikih, baik sebagai pencari ilmu maupun sebagai hakim dan juga penulis buku-buku fikih berkualitas adalah tiga hal yang dapat dijadikan pintu masuk bagi para peminat studi keislaman untuk mengkaji pemikiran-pemikiran Ibn Rusyd di bidang ini. ${ }^{1}$ Sebagaimana kita ketahui, buku Bidâyatul mujtabid, karya Ibn Rusyd ini telah dikenal oleh seluruh umat Islam di dunia, termasuk di Indonesia, terutama di pesantren-pesantren dari dahulu hingga sekarang ${ }^{2}$. Namun, yang sangat disayangkan, tulisan tentang kepiawaian Ibn Rusyd dalam bidang ini hampir terabaikan.

Bertitik tolak dari hal tersebut di atas, penulis melihat bahwa kecemerlangan Ibn Rusyd dalam bidang Fikih nampak terabaikan, atau menjadi suatu hal yang disebut ironi oleh Nurcholish Madjid. ${ }^{3}$

\footnotetext{
${ }^{1}$ Ibn Rusyd lahir di Cordova pada 520 H./1125 M. Ia lahir dari keluarga yang sangat relijius dan memiliki aktivitas keilmuan yang tinggi. Kakeknya adalah seorang Hakim di Cordova dan seorang penulis berpengaruh di Spanyol, begitu juga ayahnya.

2 H Muhadi, "PEMIKIRAN FIKIH IBN RUSYD,(Membaca Kembali Bidâyatul Mujtahid," Risâlah, Jurnal Pendidikan Dan Studi Islam 2, no. 1 (2015): 139-45.

${ }^{3}$ Madjid Nurcholish, “Kaki Langit Peradaban Islam," Jakarta: Paramadina, 1997.
} 


\section{Ibnu Rusydi \& Zaenudin}

Pemikiran Fiqih Kemaslahatan.....

\section{Landasan Teori}

\section{Ibn Rusyd dan Bidâyatul mujtahid}

Ibn Rusyd adalah salah seorang ilmuwan muslim yang cukup produktif dalam menulis. Selain mengarang buku-buku filsafat, Ibn Rusyd yang juga seorang dokter ini, banyak mengarang buku-buku fikih. Di antara buku-buku fikih karangannya, sebagaimana ditulis oleh El Abidi adalah buku ad-Da'ânî, Mukhtashar al mustashfâ fil ushul, Ad dars al kâmil fi al Fikih, Risâlatun fi ad dlahaya, Al kharaj ${ }^{4}$

Dan buku Bidâyatul mujtahid yang judul lengkapnya adalah Bidâyatul mujtahid wa nihâyatul muqtashid adalah karya Ibn Rusyd dalam bidang Fikih yang paling terkenal sekaligus paling berkualitas jika dibandingkan dengan buku-buku Fikihnya yang lain. Buku Ibn Rusyd ini selesai ditulis oleh Ibn Rusyd pada tahun 1188 M. ketika menjabat sebagai Hakim Agung di Cordoba, atau pada saat usianya sekitar 62 tahun. Buku ini memuat pandangan dan argumentasi seluruh aliran Fikih, baik mereka yang beraliran Tekstualis maupun yang beraliran Rasionalis sejak jaman sahabat hingga abad ke-11 M. ${ }^{5}$ Pada era kita sekarang ini, buku ini dikategorikan sebagai buku yang mengandung Ilmu Fikih Perbandingan atau Ilmu Perbandingan Mazhab.

Secara historis, tepatnya sejak akhir abad ke-11 M. Ilmu Fikih Perbandingan dikenal dengan sebutan Ilmu Khilaf, yaitu ilmu yang membahas pendapat dan atau pandangan para ulama yang berbeda dengan membandingkan dalil-dalil yang mereka gunakan dalam menetapkan suatu hukum. Dalam pengantar buku sejarahnya yang sangat terkenal " $A l$ Muqaddimah", Ibn Khaldun menegaskan bahwa Ilmu Khilaf (Al Khilâfìyât) adalah ilmu yang sangat berguna untuk mengetahui pendapat para Imam beserta argumentasi-argumentasi mereka dan memudahkan orang lain yang ingin menggunakannya dalam menentukan suatu hukum ${ }^{6}$. Karena pentingnya ilmu ini, maka sangatlah wajar jika para ulama Islam seperti Imam Ghazali, Imam Hanafi, Imam Syafi', Imam Maliki dan imam-imam yang lainnya dengan kadar yang berbeda antara yang satu dan yang lainnya menaruh perhatian besar terhadap ilmu ini.

Dan sebagaimana para ulama Islam di atas, Ibn Rusyd pun tidak ketinggalan. Dengan metode penulisan yang cukup berbeda dari para penulis sebelumnya yang dijadikan referensi olehnya seperti kakeknya sendiri, Ibn Rusyd melihat bahwa Ilmu Khilaf berbeda dengan Fikih. Jika Fikih hanya menerangkan suatu hukum tanpa disertai dengan dalil-dalil, atau jika pun dengan dalil, itu terbatas pada satu pendapat saja, Ilmu Khilaf mendeskripsikan suatu hukum dengan berbagai pandangan dan pendapat yang berbeda disertai dengan argumentasi dan dalildalilnya.

Karena alasan inilah mengapa Ibn Rusyd mengarang buku Bidâyatul mujtahid, suatu alasan yang bertitik tolak dari pemikirannya tentang pentingnya pintu ijtihad dibuka kembali.

\footnotetext{
${ }^{4}$ Hamādi Al-Ubaidi, “Ibn Rusyd Wa 'Ulum as-Syari'Ah Al-Islamiyah” (Beirut: Dar al-Fikr al-Arabiy, 1991).

${ }^{5}$ Dari kalangan Sahabat, Ibn Rusyd banyak menguraikan pendapat Ali, Umar, Ibn Mas'ud, Ibn 'Abbas, Zaid bin Tsabit, Ibn Umar dan Aisyah. Dari kalangan Tabi'in dan Tabi'ittabi'in, ia banyak mendeskripsikan pandangan Ikrimah, Nafi', Sa’id ibn al Musayyab, Ibn Syihâb az zuhrî, Ibrahim an nakh'i, Hammad ibn abî sulaimân, Mujâhid, Thâwus dll. Dari kalangan Imam Mazhab, selain Imam mazhab yang empat, ia banyak mengulas pandangan Imam Abi Lailâ, Sufyan ats tsauri, Laits ibn sa'd, Auzâ'i, Sufyan ibn Uyainah, Hasan al bashri, Ibn Jarîr at Thabarî, Daud azh zhâhir dll.

${ }^{6}$ Abdurrahman Ibn Khaldoun, "Al-Muqaddimah [The Introduction](Ed. and Annotated by) Abdurrahman Adil Ibn Saad," Cairo: Dar Dahabiya, 2006.
} 


\section{Ibnu Rusydi \& Zaenudin}

Pemikiran Fiqih Kemaslahatan.....

\section{Seruan Ijtihad Ibn Rusyd}

Sebagai sebuah karya ilmiah, buku Bidâyatul mujtahid tidak lahir begitu saja tanpa dilatarbelakangi keadaan-keadaan dan situasi yang menyertainya. Dan jika kita kembali ke sejarah menjelang kehadirannya, yaitu akhir abad ke-11 M., maka akan kita temukan bahwa dunia Islam pada waktu itu berada dalam kondisi yang sangat buruk di mana konflik politik melanda seluruh wilayah Islam. Pada masa kemunduran Islam yang sejatinya telah dimulai sejak akhir pemerintahan Bani Umayah dan disebut sebagai masa disintegrasi oleh Harun Nasution ini, daerah-daerah yang berada jauh dari pusat pemerintahan di Damaskus dan kemudian di Baghdad melepaskan diri dari kekuasaan Khalifah yang mengakibatkan timbulnya dinastidinasti kecil. ${ }^{7}$

Tentunya, kondisi politik yang tidak kondusif ini sangat berpengaruh pada bidangbidang lainnya seperti ekonomi, sosial dan budaya serta keilmuan. Dalam bidang yang terakhir ini, mereka tidak lagi memiliki ilmuwan-ilmuwan produktif sebagaimana pada abad-abad sebelumnya. Secara khusus di bidang Fikih, para ulama Islam tidak lagi menghasilkan karyakarya ilmiahnya dan merasa cukup dengan yang telah ada sebelumnya. Yang dilakukan mereka tidak lebih dari sekadar meringkas atau membuat penjelasan-penjelasan dari karya-karya pendahululnya Dalam kondisi yang demikian, umat Islam dilanda penyakit yang disebut dengan taqlîd, yaitu mengikuti pendapat seseorang tanpa disertai dengan ilmu, alasan, argumentasi atau dalil apa pun. ${ }^{8}$

Berkenaan dengan hal tersebut di atas, secara lebih detail, Dr. Hammadi el Abidi ${ }^{9}$ menulis empat fenomena hilangnya spirit ijtihad di kalangan ahli fikih ini. Keempat fenomena tersebut adalah:

\section{Peringkasan}

Pada satu sisi, peringkasan merupakan suatu karya ilmiah yang tentunya memiliki nilai positifnya sendiri. Tapi di sisi lain, karena ini adalah fikih, maka suatu peringkasan terhadap fikih akan menghilangkan substansi fikih itu sendiri. Menurut El Abidi, peringkasan adalah suatu penyakit karena kebosanan dan kepenatan jiwa. ${ }^{10}$

\section{Perhatian lebih kepada cabang dibanding ke pokok}

Pada saat merebaknya karya-karya peringkasan, ditemukan kesulitan memahami isinya, lahirlah karya-karya berupa penjelasan-penjelasan terhadap peringkasan tersebut yang pada akhirnya perhatian ditujukan hanya kepada masalah-masalah yang itu-itu saja dan tidak menyentuh permasalahan baru yang lebih sesuai dengan kondisi jaman.

\section{Debat kusir}

Para ahli fikih sangat intens dalam beradu argumentasi dan dalil-dalil dalam mengutarakan pendapat dan pandangan mereka dalam suatu hukum.. Namun, adu argumentasi tersebut tak lebih dari sekadar debat yang tujuannya bukan untuk mencari kebenaran, tapi untuk memenangkan pertarungan dan mempertahankan pendapat mereka masing-masing.

\section{Asumsi-asumsi Fikih yang tidak logis}

\footnotetext{
${ }^{7}$ Harun Nasution, “Islam Ditinjau Dari Berbagai Aspeknya, Jilid I," Cet. V, 1985.

${ }^{8}$ Muhammad bin Ali As-Syaukani, “Fathu Al-Qadi> R,” Libanon: Darul Ma'rifah, 2007.

${ }^{9}$ Ia adalah salah seorang Dosen pada mata kuliah Ilmu Perbandingan Mazhab di Universitas Zaitunah, TunisTunisia.

${ }^{10}$ Al-Ubaidi, "Ibn Rusyd Wa 'Ulum as-Syari’Ah Al-Islamiyah.”
} 


\section{Ibnu Rusydi \& Zaenudin}

Pemikiran Fiqih Kemaslahatan......

Para ahli fikih banyak mengeluarkan asumsi-asumsi yang mustahil dan mengatakan bahwa inilah ilmu. Contoh asumsi yang mereka ajukan adalah bagaimana jika manusia berubah menjadi hewan, apakah ia tetap terbebani oleh kewajiban atau tidak lagi terbebani? Kemudian, bagaimana jika manusia ingin menikah dengan jin apakah diberlakukan syarat-syarat nikah yang biasa berlaku pada pernikahan antara manusia dengan manusia lainnya ${ }^{11}$

Di samping keempat fenomena di atas, El Abidi juga menambahkan, bahwa hilangnya spirit ijtihad diperparah oleh kondisi para pengikut mazhab fikihnya yang terlalu mengagungkan para Imamnya. Inilah yang disebut dengan fanatisme mazhab. Sebagai contoh, sebagaimana ditulis El Abidi ${ }^{12}$, adalah Abulmazhfar As Sam'ani yang pindah dari mazhab Syafi'i ke mazhab Hanafi, kemudian kembali lagi ke mazhab sebelumnya. Ketika ditanya mengapa ia melakukan hal demikian, ia menjawab bahwa pada suatu malam ia bermimpi bertemu Tuhannya dan mengatakan: "Kembalilah kepada Kami wahai Abulmazhfar".

Selain itu, Sebagian para pengikut mazhab Hanafi menyatakan bahwa nabi Isa ketika hadir kembali ke dunia pada akhir jaman nanti akan mengikuti mazhab Hanafi. ${ }^{13}$

Kondisi demikianlah yang dialami oleh Ibn Rusyd, suatu kondisi yang membawanya menjadi salah seorang ilmuwan muslim yang mewajibkan dibukanya kembali pintu ijtihad sebagaimana yang ditulisnya dalam Bidâyatul mujtabid: "Kami tulis buku ini, tidak lain adalah agar para ahli fikih mencapai derajat mujtahid". ${ }^{14}$ Bagaimana caranya? Caranya adalah dengan mengeluarkan segala kemampuan yang ada untuk menggali nilai-nilai Islam dan menerapkannya sesuai dengan situasi dan kondisi yang ada. Derajat mujtahid sendiri tidak akan dapat diperoleh seseorang hanya dengan menghapal hukum-hukum dari berbagai permasalahan saja tanpa dibarengi dengan kapasitas yang cukup di bidang Ushul fikih, bahasa Arab, dan Filologi, meskipun ia memiliki kualitas hapalan yang sangat tinggi.

Dalam hal pemahaman terhadap Islam yang sering dipersempit oleh sebagian umat Islam dengan fikih, Ibn Rusyd sangat menentang taqlid dan fanatisme mazhab, suatu pandangan yang juga disuarakan oleh para reformer dan pembaharu Islam seperti Muhammad Abduh di Mesir dan KH. Ahmad Dahlan di Indonesia dengan tujuan memberikan penyadaran dan demi kemajuan bagi umat Islam yang seakan larut dalam pandangan keislamannya yang sempit.

Dengan demikian, Ibn Rusyd melalui Bidâyatul mujtabid-nya sangat memperhatikan masalah-masalah keislaman dan peduli dengan umat Islam. Karena kepeduliannya tersebut, ia menyerukan dibukanya kembali pintu ijtihad yang sebelumnya ditutup dengan harapan dapat membuka pikiran umat Islam bahwa para Imam Mazhab bukanlah Nabi atau pun Rasul yang diutus oleh Allah Swt yang tidak mungkin melakukan suatu kesalahan. Mereka adalah manusia biasa sehingga kita bisa saja berbeda pendapat dengan mereka.

\footnotetext{
${ }^{11}$ Abu Hamid Al-Ghazali, "Deliverance from Error," Louisville: Fons Vitae, 2000.

${ }^{12}$ Sumadi Sumadi, "IDEOLOGI BIAS GENDER DALAM LEMBARAN FIKIH POPULER DI INDONESIA," Al-Afkar, Journal For Islamic Studies 1, no. 1 (2018): 1-15.

${ }^{13}$ Al-Ubaidi, "Ibn Rusyd Wa 'Ulum as-Syari'Ah Al-Islamiyah."

${ }^{14}$ Ibnu Muhammad Ibnu Rusyd and M Ibn Ahmad, "Bidâyatul Mujtahid Wa Muqtasid” (Beirut: Darul Qalam, 1998).
} 


\section{Ibnu Rusydi \& Zaenudin}

Pemikiran Fiqih Kemaslahatan.....

\section{Syariat Islam dan Kemaslahatan dalam Pandangan Ibn Rusyd}

Siapa pun yang melakukan pengkajian dan penelitian terhadap syariat Islam (fikih), akan mendapatkan bahwa syariat Islam memiliki tujuan moral dan sosial yang sangat tinggi ${ }^{15}$. Tidak ada seorang pun yang dapat mengingkari realita ini, bahkan oleh orang yang berusaha mengingkarinya.

Pernyataan yang bukan hanya isapan jempol belaka ini juga dianut oleh Ibn Rusyd dalam Bidâyatul mujtahid. Dan pandangan-pandangan Ibn Rusyd dalam hal hubungan antara syariat Islam dan kemaslahatan ini terkait dengan suatu ilmu yang disebut dengan Ilmu al maqâshid atau Maqâshidus syar̂̉ah, yaitu suatu ilmu yang didasari oleh suatu prinsip bahwa segala perbuatan dan atau hukum yang ditetapkan oleh Allah Swt pasti memiliki arti dan hikmah serta tujuannya sendiri yang tidak mungkin sia-sia. Arti dan hikmah inilah yang disebut dengan kemaslahatan. ${ }^{16}$

Dalam Al Quran banyak disebutkan secara eksplisit bahwa syariat yang diturunkan oleh Allah Swt tidak luput dari kemaslahatan sebagai tujuannya, seperti pada ayat tentang wudlu. Allah Swt berfirman:

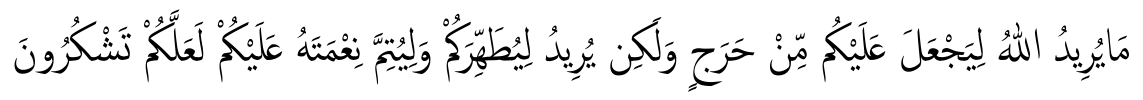

Dalam ayat di atas Allah Swt menegaskan bahwa perintah wudlu bukan untuk menyulitkan manusia tapi untuk kemaslahatan dirinya yaitu berupa kesucian diri dan kesempurnaan nikmat dari Allah Swt.

Kemudian ayat tentang shalat. Allah Swt berfirman:

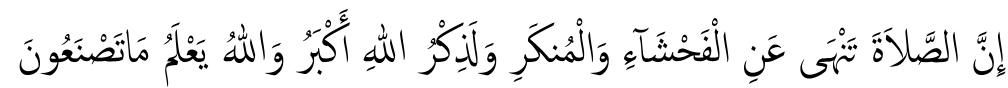

Dalam ayat ini Allah Swt menandaskan bahwa perintah shalat ditetapkan untuk kemaslahatan manusia yaitu agar dirinya terjaga dari segala tindak kejahatan yang mungkin dilakukannya.

Begitu pula dengan ayat tentang qishas. Allah Swt.

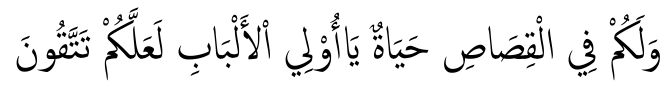

Allah Swt adalah pencipta manusia yang tentunya Maha Mengetahui apa yang dibutuhkan oleh manusia dalam kehidupannya. Oleh karena itu, Ia menetapkan hukuman qishas

\footnotetext{
${ }^{15}$ Ibnu Rusydi, “FILSAFAT POLITIK ISLAM; Sebuah Pengantar," Risâlah, Jurnal Pendidikan Dan Studi Islam 2, no. 1 (2015): 110-23.

${ }^{16}$ Berkenaan dengan ilmu al maqâshid ini - sebagaimana diuraikan oleh El Abidi-, ilmuwan muslim yang pertama menaruh perhatian terhadapnya - adalah Ibrahim an nakh'i (w:96 H) dari kalangan Tabi'in dan Syekh Hammad ibn Abi Sulaiman, salah seorang guru Abu Hanifah. Kemudian Al 'Izz ibn Abdissalam yang mengarang buku al Qawẩid. Setelah itu muncul Najmuddin At Thufi yang mengarang buku berjudul al mashâlih al mursalah. Setelah At Thufi, datang Abu Ishaq As Syatibi pada abad ke-8 H., seorang keturunan Granada, Spanyol. Yang terakhir ini adalah ilmuwan Muslim yang pertama kali mengkhususkan pembahasan tentang al maqâshid dalam bukunya yang berjudul al Muwâfaqât.
} 


\section{Ibnu Rusydi \& Zaenudin}

Pemikiran Fiqih Kemaslahatan......

bagi pelaku pembunuhan adalah untuk kemaslahatan manusia itu sendiri, yaitu berupa kehidupan di mana ketika seseorang yang membunuh diberi hukuman mati, akan berdampak besar bagi orang lain sehingga tindak pidana pembunuhan yang sangat merugikan manusia dapat ditekan seminimal mungkin.

Berdasarkan kajian terhadap ayat-ayat di atas, As Syathibi dengan tegas mengatakan bahwa hal ini (adanya kemaslahatan manusia di dalam hukum yang ditetapkan oleh Allah Swt berlaku bagi semua hukum-hukum-Nya yang lain meskipun tidak secara eksplisit diungkapkan di dalam Al- Quran. ${ }^{17}$

Para ulama Fikih yang menulis tentang maqâshidussyari'ah atau ilmu al maqâshid membagi tujuan syariat baik dalam peribadatan, hubungan antar manusia, maupun adat istiadat menjadi tiga, Pertama: untuk kepentingan yang mendesak (primer). Tujuan ini mencakup lima hal yaitu untuk memelihara agama, memelihara akal, memelihara jiwa, memelihara harta dan memelihara keturunan. Tujuan ini menjadi suatu hal yang sangat mendesak karena tanpa kelima hal tersebut, kehidupan manusia di dunia dan akhirat akan rusak. Kedua: untuk kepentingan sekunder. Contohnya adalah makan, minum, melakukan akad persewaan, jual beli, dan lain-lain. Meskipun tujuan ini sangat dibutuhkan oleh manusia dalam kehidupannya, namun derajatnya masih di bawah tujuan primer karena pada saat kebutuhan ini tidak terpenuhi, kerusakan yang diakibatkannya tidak separah kerusakan yang ditimbulkan pada saat kebutuhan yang pertama tidak terpenuhi. Yang ketiga: untuk kepentingan tersier, yaitu segala hal yang berkaitan dengan adat istiadat dan etika yang baik, seperti selalu menjaga kebersihan, menjaga kerapihan dalam berpakaian, menjalankan amalan-amalan sunnah, menjalankan etika kesopanan dalam makan dan lain sebagainya. ${ }^{18}$

Pada dasarnya, Ibn Rusyd tidak berbeda dengan para ulama fikih sebelumnya dalam hal hubungan antara syariat dengan kemaslahatan. Yang membedakan antara Ibn Rusyd dan yang lainnya adalah penekanannya saja. Jika para ahli fikih menekankan sisi kemaslahatan dan kepentingan, Ibn Rusyd menekankan pandangannya pada sisi moral. Ia berpendapat bahwa syariat itu lahir untuk memperbaiki akhlak manusia. Dalam hal ini El Abidi menyatakan bahwa Ibn Rusyd adalah satu-satunya ahli fikih yang membangun tujuan syariat di atas fondasi moral (akhlak). ${ }^{19}$

Berikut ini penulis uraikan contoh pemikiran Ibn Rusyd tentang hubungan antara syariat dan kemaslahatan yang dibangunnya di atas fondasi akhlak dalam Bidâyatul mujtahid:

\section{Pengambilan kembali hadiah yang telah diberikan seseorang kepada orang lain.}

Apakah hukum mengambil kembali hadiah yang telah kita berikan kepada oranglain? Sebagian ahli Fikih mengatakan bahwa hal itu boleh-boleh saja dan sebagian yang lainnya mengatakan tidak boleh. Dalam hal ini ${ }^{20}$, Imam Maliki mengatakan bahwa hal itu tidak boleh kecuali yang dilakukan orang tua terhadap anaknya. Itu pun dengan syarat barang yang dihadiahkan tidak berpindah tangan, misalnya dengan adanya pernikahan dan lain-lain. Sedangkan Ibn Rusyd menyatakan bahwa hal tersebut tidak boleh dilakukan karena alasan

\footnotetext{
${ }^{17}$ As Syathibi, Abu Ishaq, Al Muwafaqat, jilid 2,Beirut, Darul ma'rifah, t.t. hal: 7.

${ }^{18}$ Lihat penjelasan yang lebih detail tentang tiga tujuan syariat ini dalam buku Al Muwâfaqât karya Imam Abu Ishaq As Syathibi, jilid 2 hal: 8-12.

${ }^{19}$ El Abidi, Ibn Rusyd wa Ulûm as-Syarîah, h. 107.

${ }^{20}$ Sasa Sunarsa, "TAFSIR THEORY; STUDY ON AL-QURAN METHODS AND RECORDS.(TEORI TAFSIR; KAJIAN TENTANG METODE DAN CORAK TAFSIR AL-QURAN)," Al-Afkar, Journal For Islamic Studies 3, no. 1 (2019): 247-59.
} 


\section{Ibnu Rusydi \& Zaenudin}

Pemikiran Fiqih Kemaslahatan......

akhlak. Ia mengatakan: "Mengambil kembali hadiah yang telah diberikan kepada orang lain bukanlah akhlak yang terpuji, padahal nabi Muhammad Saw diutus untuk menyempurnakan akhlak. $^{21}$

\section{Masalah anak yang dilahirkan oleh seorang hamba sahaya.}

Dalam masalah anak yang dilahirkan oleh seorang hamba sahaya, para ahli Fikih sependapat tentang hukumnya bahwa anak itu adalah anak wanita tersebut jika ia dinikahi oleh tuannya dalam keadaan belum hamil darinya di mana setelah kematiannya ibu tersebut menjadi bebas (bukan hamba sahaya lagi). Tapi jika ia dinikahi oleh tuannya pada saat ia hamil, para ahli Fikih berbeda pendapat. Imam Malik mengatakan bahwa ia bukanlah anaknya sehingga ia tetaplah hamba sahaya meskipun tuannya telah meninggal. Yang lain mengatakan bahwa ia adalah anaknya secara mutlak.

Ibn Rusyd dalam masalah ini menolak pendapat Imam Malik. Ia mengatakan bahwa ia adalah anak wanita tersebut dalam kondisi apa pun dan bukanlah suatu akhlak yang terpuji seandainya tuannya menjual wanita tersebut padahal Rasulullah Saw bersabda bahwa ia diutus untuk menyempurnakan akhlak. ${ }^{22}$

\section{Simpulan}

Demikianlah deskripsi pemikiran Ibn Rusyd dalam bidang Fikih yang memiliki perbedaan dengan kebanyakan para ulama pada jamannya. Namun satu hal yang kiranya perlu ditekankan di sini yaitu bahwa yang dilakukan oleh Ibn Rusyd adalah suatu ijtihad yang memiliki kemungkinan benar dan salah sekaligus sebagaimana yang dilakukan oleh para ulama Fikih lainnya. Dan yang namanya ijtihad-sebagaimana kita ketahui- jika benar akan mendapatkan pahala dua kali dan jika salah akan mendapatkan pahala satu kali.

Adalah suatu hal yang sangat manusia jika terjadi perbedaan pendapat di antara manusia karena dalam posisi itulah manusia diciptakan. Maka dari itu, perbedaan bukanlah suatu hal yang perlu dipermasalahkan. Yang jadi permasalahan adalah bagaimana menyikapi perbedaan itu. Jika Islam mengajarkan umatnya untuk bertoleransi terhadap pemeluk agama lain, maka toleransi intern umat Islam yang lebih dikenal dengan istilah ukhuwah Islamiyah itu lebih dianjurkan lagi.

Oleh karena itu, sangat disayangkan sekali kejadian yang menimpa Ibn Rusyd ketika buku-bukunya tentang filsafat dibakar, jabatannya sebagai Hakim Agung dicopot, bahkan dicap sebagai kafir oleh Khalifah Ya'qub Ibn Yusuf pada tahun 1195 M. hanya karena pemikiranpemikiran filsafatnya yang berbeda dengan mayoritas umat Islam waktu itu.

\footnotetext{
${ }^{21}$ Ibn Rusyd, Bidâyatul mujtabid, jilid 2 h. 271.

${ }^{22}$ Ibn Rusyd, Bidâyatul mujtabid, jilid 2 h. 321.
} 


\section{DAFTAR PUSTAKA}

Al-Ghazali, Abu Hamid. "Deliverance from Error." Louisville: Fons Vitae, 2000.

Al-Ubaidi, Hamādi. "Ibn Rusyd Wa 'Ulum as-Syari'Ah Al-Islamiyah.” Beirut: Dar alFikr al-Arabiy, 1991.

As-Syaukani, Muhammad bin Ali. "Fathu Al-Qadi> R.” Libanon: Darul Ma'rifah, 2007.

Ibn Khaldoun, Abdurrahman. "Al-Muqaddimah [The Introduction](Ed. and Annotated by) Abdurrahman Adil Ibn Saad." Cairo: Dar Dahabiya, 2006.

Muhadi, H. "PEMIKIRAN FIKIH IBN RUSYD,(Membaca Kembali Bidâyatul Mujtahid." Risâlah, Jurnal Pendidikan Dan Studi Islam 2, no. 1 (2015): 139-45.

Nasution, Harun. "Islam Ditinjau Dari Berbagai Aspeknya, Jilid I.” Cet. V, 1985.

Nurcholish, Madjid. "Kaki Langit Peradaban Islam.” Jakarta: Paramadina, 1997.

Rusyd, Ibnu Muhammad Ibnu, and M Ibn Ahmad. "Bidâyatul Mujtahid Wa Muqtasid.” Beirut: Darul Qalam, 1998.

Rusydi, Ibnu. "FILSAFAT POLITIK ISLAM; Sebuah Pengantar." Risâlah, Jurnal Pendidikan Dan Studi Islam 2, no. 1 (2015): 110-23.

Sumadi, Sumadi. "IDEOLOGI BIAS GENDER DALAM LEMBARAN FIKIH POPULER DI INDONESIA.” Al-Afkar, Journal For Islamic Studies 1, no. 1 (2018): 1-15.

Sunarsa, Sasa. "TAFSIR THEORY; STUDY ON AL-QURAN METHODS AND RECORDS.(TEORI TAFSIR; KAJIAN TENTANG METODE DAN CORAK TAFSIR AL-QURAN)." Al-Afkar, Journal For Islamic Studies 3, no. 1 (2019): 247-59. 